\title{
Fat Body Lipid Alterations in White Grub Adults of Oryctes rhinoceros
}

\author{
Suvarna More \\ Department of Zoology, P.V.P. Mahavidyalaya, Kavathe Mahankal, Dist. Sangli (M.S.), India 416405
}

\begin{abstract}
The fat body plays major roles in the life of insects. It is a dynamic tissue involved in multiple metabolic functions. One of these functions is to store and release energy in response to the energy demands of the insect. Insects store energy reserves in the form of glycogen and triglycerides in the adipocytes, the neutral lipids $(N L)$ and phospholipids $(P L)$ with their constituents were studied in the fat body of male and female adults of Oryctes rhinoceros, by employing thin layer chromatography (TLC) and bioassay technique. The quantities of neutral lipids in male and female fat body were measured 57.501 and $45.894 \mathrm{mg} / \mathrm{gm}$ wet weight of tissues respectively. The main component of neutral lipids was triacylglycerol. The phospholipid values in male and female were 17.26 and $16.85 \mathrm{mg} / \mathrm{gm}$ wet weight of tissues respectively. The NL: PL ratio in male and female adults was recorded to 3:1. The neutral lipids found in six forms. Triacylglycerol was the main component, monoacylglycerol, diacylglycerol, cholesterol, were moderate and cholesterol ester and free fatty acids low in quantity. Phospholipids exhibited seven constituents; phosphatidyl-choline and phosphatidyl-ethanolamine in high concentration, Lysophosphatidyl-choline and sphingomyelin in moderate concentration, and phosphatidyl-inositol, phosphatidyl-serine and phosphatidic acid low in quantity.
\end{abstract}

Keywords: lipids, Fat body. Thin layer chromatography, and Oryctes rhinoceros.

\section{Introduction}

The white grub have become known polyhagus and found in a particular type of agro ecosystem. In India Lefray, [29] Ghosh [17] studied the white grubs of sugarcane. White grubs are most destructive insect pest all over the world. Adult Oryctes rhinoceros is the pest of coconut trees; responsible for causing considerable reduction in yields. Lipids are bio-chemically important components of insect. Lipid performs a variety of functions in insect physiology. Triacylglycerol is utilized for biological energy [13]. The insect fat body plays an essential role in energy storage and utilization. It is an organ of great biosynthetic and metabolic activity [27]. Fatty acids stored in the lipid droplets of the fat body are mobilized for a number of purposes, to flight muscles, in the form of diglyceride; to the ovaries; and the overall maintenance of the metabolic activity. Fat body lipids are commonly secreted into the hemolymph as diacylglycerol, which is transported to the tissues by the insect lipoprotein, lipophorin $[31,33]$. The utilization of lipids in insects has been reviewed on several occasions [6]; [11], [14]. Fat body is a multifunctional organ in $D$. melanogaster and Bombyx mori [10], [24]. Fat body cells control the synthesis and utilization of energy reserves. [25].The fat body is structurally heterogeneous and functions of the fat body are present all over the tissue [20],[23]. Triglycerides are the major component of the lipid droplets, and Fatty acids stored as triglyceride can be used for energy production [12], [3]. Triglyceride is stored in an anhydrous form, and also has a higher caloric content. The conversion of carbohydrates, a major component of the insect diet, to lipid in the fat body is well documented [9],[21], [22], [26], [34]. Almost all tissues can synthesize and store triglyceride in small lipid droplets, but adipocytes are specialized cells for lipid storage [30]. Fat body adipocytes cells are able to store large amounts of triglycerides [12]. Accumulation of lipids by diapausing insects is well documented [14]. A lipid droplet consists of a core of neutral lipids (triglyceride and cholesterol esters) surrounded by a monolayer of phospholipid and cholesterol, [7], [8]. The significance of phospholipids with PC and PE was explained by Locke and Krishnan [28].

\section{Materials and Methods}

The late third instars larvae and prepupae were collected from dunghill of Agriculture College, near the Shivaji University, campus Kolhapur, (M.S.). They were reared at laboratory and adults were used for fat body lipid extraction.

\section{I) Extraction of Lipids}

The fat body of male and female adults were weighed and homogenized with $20 \mathrm{ml}$ of chloroform-methanol (2:1 v/v) at room temperature. Five male and five female adults were taken for the present investigation the homogenates were allowed to stand for $2-3$ hours at $4^{0} \mathrm{c}$ and filtered. The filtrate was washed according to Floch et.al; [16] and evaporated in vacuum at $40^{\circ} \mathrm{c}$. The lipid samples were weighed and preserved at $-20^{\circ} \mathrm{c}$ until further use. The total lipid in the sample was determined gravimetrically.

\section{II) Separation of Neutral Lipids and Phospholipids}

The neutral lipids and phospholipids were separated by thin layer chromatography (TLC) using silica gel $\mathrm{G}$ and about 200 mesh containing $\mathrm{CaSo} 4$, as a binder, (E Merck Germany). The TLC plates $(20 \times 20 \mathrm{~cm})$ were prepared according to Wagner et.al [36]. The known quantities of samples dissolved in chloroform were applied with Hamilton's micro syringe (No.8206-B) on activated plates. For neutral lipid the plates were developed in hexane (B.P. $\left.65-70^{\circ} \mathrm{c}\right)$ diethyl ether - acetic acid $(85: 15: 2 \mathrm{v} / \mathrm{v})$ as recommended by Gloster and Flecter [18]. The phospholipid plates were developed in chloroform- 


\section{International Journal of Science and Research (IJSR) \\ ISSN (Online): 2319-7064}

Index Copernicus Value (2013): 6.14 | Impact Factor (2015): 6.391

methanol-ammonia (115:45:5 v/v) as recommended by Barwal and Kalra [4]. The standards of neutral lipids and phospholipids (Sigma,U.S.A.) were co-chromatographed in each respective run and then plates were kept in iodine chamber for identification of individual spots of lipids.

\section{III) Estimation of Neutral Lipids and Phospholipids.}

The iodine was allowed to evaporate and the silica gel from the individual spots of glycerides was scraped and eluted in $1 \mathrm{ml}$ of diethyl-ether and assayed according to Viogue and Holman [35]. The cholesterol and its ester were estimated according to Abell et.al [1]. The rest of the neutral lipid components were assayed titrometrically by the method of Skipski et.al [32]. The phospholipid was determined by the method of Marinetti [30].

\section{Results}

\section{i) Neutral Lipids}

The TLC separation of various neutral lipid components are illustrated in plate No.1, Fig. A; whereas, Table No.1 exhibits quantitative variations in the neutral lipid components. The neutral lipids in male and female fat bodies were measured $49.221 \pm 2.15$ and $63.894 \pm 3 . .23$ $\mathrm{mg} / \mathrm{gm}$. wet weight of tissues respectively. The neutral lipids consists of six components; of these triacylglycerol (TG) being the major component. Monoacylglycerol (MG), diacylglycerol (DG) and cholesterol (CHO) were found moderate in concentration; whereas free fatty acids (FFA) and cholesterol ester (CE) were occurred low in quantities. The TG concentration in fat body of male and female was about 40.42 and $50.05 \mathrm{mg} / \mathrm{gm}$ wet weight of tissues respectively.

\section{ii) Phospholipids}

The phospholipids are illustrated in plate No.1, Fig B and Table 2. The phospholipids in male and female fat body were measured $23.266 \pm 0.76$ and $17.349 \pm 0.93$ $\mathrm{mg} / \mathrm{gm}$. wet weight of tissues respectively. The TLC separation of phospholipids included following constituents; phosphatidyl-choline (PC), phosphatidylethanolamine (PE), Lysophosphatidyl-choline (LPC), sphingomyelin (SPG), phosphatidyl-inositol (PI), phosphatidyl-serine (PS) and phosphatidic acid (PA). Among the phospholipids PC and PE were predominant. In male and female fat bodies they measure about $382.1 \pm$ $4.57,360.3 \pm 13.01 \mu \mathrm{g}-\mathrm{P} / \mathrm{gm}$ and $285.1 \pm 13.9,280.5 \pm$ $13.7 \mu \mathrm{g}-\mathrm{P} / \mathrm{gm}$ wet weight of tissues respectively. The LPC and SPG were estimated in moderate concentration, whereas PI, PS and PA less in amount.

\section{PIATE NO.- 1}
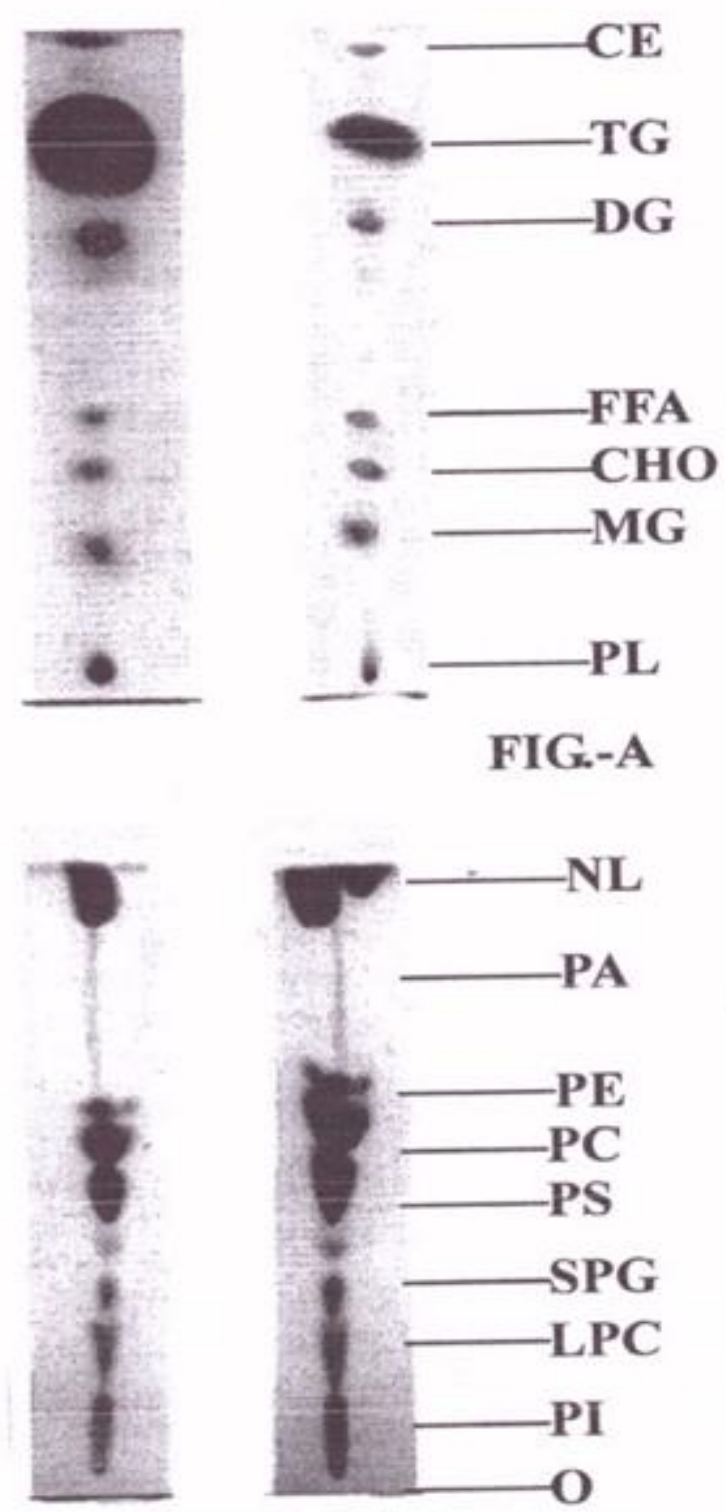

Female Fat Bodies

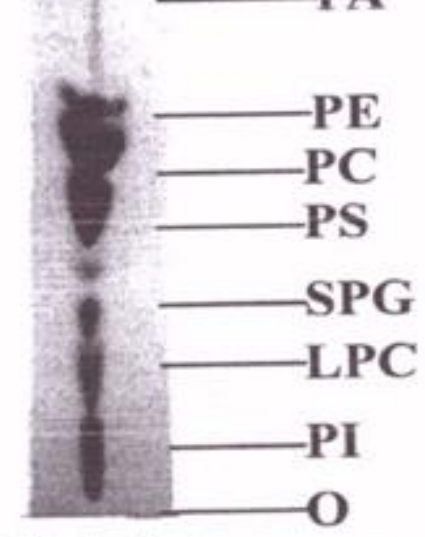

Male Fat Bodies

Table 1: Alterations in total lipids, neutral lipids and its components in the male and female Fat Bodies of $O$. rhinoceros

\begin{tabular}{|c|c|c|}
\hline Lipid Type & Male Fat Bodies & Female Fat Bodies \\
\hline $\begin{array}{c}\text { Total } \\
\text { Lipids }\end{array}$ & $72.487 \pm 2.64$ & $81.894 \pm 3.60$ \\
\hline $\begin{array}{c}\text { Neutral } \\
\text { Lipids }\end{array}$ & $49.221 \pm 2.15$ & $63.894 \pm 3.23$ \\
\hline MG & $1.615 \pm 0.15$ & $3.335 \pm 0.16$ \\
\hline CHO & $1.826 \pm 0.09$ & $01.868 \pm 0.16$ \\
\hline FFA & $0.591 \pm 0.04$ & $2.639 \pm 0.08$ \\
\hline DG & $3.867 \pm 0.16$ & $4.834 \pm 0.06$ \\
\hline TG & $40.42 \pm 2.832$ & $50.05 \pm 1.60$ \\
\hline CE & $0.902 \pm 0.05$ & $1.168 \pm 0.12$ \\
\hline
\end{tabular}




\section{International Journal of Science and Research (IJSR) \\ ISSN (Online): 2319-7064}

Index Copernicus Value (2013): 6.14 | Impact Factor (2015): 6.391

The values for total lipids, neutral lipids and its components are expressed as $\mathrm{mg} / \mathrm{gm}$. wet weight of tissues.

Table 2: Alterations in phospholipids and its constituents in male and female Fat Bodies of $O$. rhinoceros

\begin{tabular}{|c|c|c|}
\hline Lipid Type & Male Fat Bodies & Female Fat Bodies \\
\hline Phospholipids & $23.266 \pm 0.76$ & $17.349 \pm 0.93$ \\
\hline PI & $25.70 \pm 0.75$ & $20.70 \pm 0.62$ \\
\hline LPC & $66.21 \pm 2.76$ & $36.47 \pm 2.12$ \\
\hline SPG & $57.31 \pm 2.56$ & $33.22 \pm 1.73$ \\
\hline PS & $16.18 \pm 0.75$ & $17.24 \pm 0.51$ \\
\hline PC & $382.1 \pm 4.57$ & $285.1 \pm 13.9$ \\
\hline PE & $360.3 \pm 13.01$ & $280.5 \pm 13.7$ \\
\hline PA & $22.87 \pm 0.64$ & $20.70 \pm 1.03$ \\
\hline
\end{tabular}

The values of phospholipids are expressed as $\mathrm{mg} / \mathrm{gm}$. wet weight of tissues; whereas, values of individual constituents are expressed as $\mu \mathrm{g}-\mathrm{P} / \mathrm{gm}$. wet weight of tissues.

\section{Discussion}

The male Fat bodies of Oryctes rhinoceros exhibited low concentration of lipids than the female. The NL: PL ratio in male and female adult fat bodies was $2: 1$ and $4: 1$ respectively, indicated that the neutral lipids was dominated over the phospholipid. Among the neutral lipids TG constitute the major component. The TG of the neutral lipids in male and female fat bodies was 40.42 and 50.05 respectively. Phospholipids are expressed as $\mathrm{mg} / \mathrm{gm}$ wet weight of tissues and their values in male and female fat bodies of $O$ rhinoceros were 23.266 and $17.349 \mathrm{mg} / \mathrm{gm}$, respectively. In the present investigation male fat bodies exhibited high phosphplipid contents than female fat bodies. Among the phospholipids the PC and PE were major constituents. The PC: PE ratio was 1:1 which indicated that the $\mathrm{PC}$ and $\mathrm{PE}$ are equal in their values. Lipid stores remain stable during the remainder of larval life and are carried over into pupae and pharate adults [22]. This is good agreement with our findings. However, much of the glycogen serves as an energy source during the postfeeding larval period, and the rest is preserved to be utilized in pupae and adults. A similar pattern in the utilization of energy reserves is reported for crickets during the final nymphal instar and the molt to the adult [2]. Therefore both triglyceride and glycogen are stored in the fat body. Fat reserves are used by insects to meet their energy demand during diapause [19], and to fuel prolonged periods of flight [5]. The fat body plays a major role in intermediary metabolism and it is the central storage depot of nutrients and energy reserves. Fat body energy reserves are mobilized in response to the energy demands of other tissues. Lipids always represent the major component of the fat body and the main source of metabolic fuel. Triglycerides, the major lipid form, are stored in the core of the lipid droplets; Lipid droplets are dynamic organelles whose metabolic activity is dependent on the protein components [15].

\section{Acknowledgements}

Author thanks to Prof. V A. Sawant Dept of Zoology Shivaji University Kolhapur for his encouragement.

\section{References}

[1] Abell, L.L., Levy, B.B., Brodie B.B., and Kendall, F.F. : A simplified method for the estimation of total cholesterol in serum and demonstration of its specificity., J. Biol. Chem. 195, 357-359, 1952.

[2] Anand AN, Lorenz MW. Age-dependent changes of fat body stores and the regulation of fat body lipid synthesis and mobilisation by adipokinetic hormone in the last larval instar of the cricket, Gryllus bimaculatus. J Insect Physiol. 54:1404-12, 2008.

[3] Athenstaedt K, Daum G. The life cycle of neutral lipids: synthesis, storage and degradation. Cell Mol Life Sci. 63:1355-69; 2006.

[4] Barwal, R.N. and Kalra, R.L. : Lipids lindane susceptible and resistant strains of T. castaneu., Indian J. Expt. Biol., 26, 228-234;1988.

[5] Beenakkers AMT, Vanderhorst DJ, Vanmarrewijk WJA. Insect flight metabolism. Insect Biochem. 14:243-60;1984.

[6] Beenakkers AM, Van der Horst DJ, Van Marrewijk WJ. Insect lipids and lipoproteins, and their role in physiological processes. Prog Lipid Res. 24:19-67. 1985.

[7] Bickel PE, Tansey JT, Welte MA. PAT proteins, an ancient family of lipid droplet proteins that regulate cellular lipid stores. Biochim Biophys Acta.1791:41940; 2009.

[8] Brasaemle DL. Thematic review series: adipocyte biology. The perilipin family of structural lipid droplet proteins: stabilization of lipid droplets and control of lipolysis. J Lipid Res. 48:2547-59; 2007.

[9] Briegel H. Metabolic relationship between female body size, reserves, and fecundity of Aedes aegypti. J Insect Physiol. 36:165-72; 1990.

[10] Cheng DJ, Xia QY, Zhao P, Wang ZL, Xu HF, et al. EST-based profiling and comparison of gene expression in the silkworm fat body during metamorphosis. Arch Insect Biochem Physiol. 61:10$23 ; 2006$.

[11] Canavoso LE, Jouni ZE, Karnas KJ, Pennington JE, Wells MA. Fat metabolism in insects. Annu Rev Nutr. 21:23-46; 2001.

[12] Dean RL, Collins JV, Locke M. Structure of the fat body. In: Kerkut GA, Gilbert LI, editors. Comprehensive Insect Physiology, Biochemistry, and Pharmacology. New York: Pergamon; pp. 155-210; 1985.

[13]Downer RGH, Physiological and environmental consideration in insect bioenergetics, In energy metabolism in Insects, Edited By R.G.H. Downer, 1981, 1-17, Plenum Press New York, 1997.

[14]Downer RGH, Matthews JR. Patterns of lipid distribution and utilization in insects. Am Zool. 16:733-45; 1076

[15] Estela L. Arrese and Jose L. Soulages : Insect fat body : Energy, Metabolism and Regulation, $\underline{\text { Annu }}$ Rev Entomol. 55: 207-225; 2010.

[16] Folch, J., Lees, M. and Sloane-Stanley A simple method for the isolation and purification of the total lipid from animal tissue. G.H. J.Biol. Chem 226; 497509; 1957.

[17] Ghosh G. L. : Ind. J. Agri. Sci., 7 907-931; 1937. 


\section{International Journal of Science and Research (IJSR) \\ ISSN (Online): 2319-7064}

Index Copernicus Value (2013): 6.14 | Impact Factor (2015): 6.391

[18] Gloster, J. Flectar, R.F., Quantitative analysis of serum lipids with thin layer chromatography., clin. Chim. Acta., 13, 235-240; 1966.

[19]Hahn DA, Denlinger DL. Meeting the energetic demands of insect diapause: nutrient storage and utilization. J Insect Physiol. 53:760-73; 2007.

[20] Haunerland NH, Shirk PD. Regional and functional differentiation in the insect fat body. Annu Rev Entomol. 40:121-45; 1995.

[21] Hines WJW, Smith MJH. Some aspects of the intermediary metabolism in the desert locust, Schistocerca gregaria Forskål. J Insect Physiol. 9:463$68 ; 1963$.

[22] Inagaki S, Yamashita O. Metabolic shift from lipogenesis to glycogenesis in the last instar larval fat body of the silkworm, Bombyx mori. Insect Biochem. 16:327-31; 1986.

[23] Jensen PV, Borgesen LW. Regional and functional differentiation in the fat body of pharaoh's ant queens, Monomorium pharaonis (L.) Arthropod Struct Dev. 29:171-84. 2000.

[24] Jiang Z, Wu XL, Michal JJ, McNamara JP. Pattern profiling and mapping of the fat body transcriptome in Drosophila melanogaster. Obes Res. 13:1898-904; 2005.

[25] Keeley LL. Biochemistry and physiology of the insect fat body. In: Kerkut GA, Gilbert LI, editors. Comprehensive Insect Physiology, Biochemistry and Pharmacology. Vol. 3. New York: Pergamon; pp. 211-28; 1985.

[26] Kim SK, Rulifson EJ. Conserved mechanisms of glucose sensing and regulation by Drosophila corpora cardiaca cells. Nature. 431:316-20; 2004

[27] Law JH, Wells MA. Insects as biochemical models. J Biol Chem. 264:16335-38; 1989.

[28] Lefroy H. M. : Ent. Memories, 11, 143-146; 1900.

[29] Locke M and Krishnan N, J. Phospholipids and fatty acid composition of $\mathrm{T}$. granarium and biosynthesis of fatty acids during development, Comp. Biochem. Physiol., 39, 183-194; 1971.

[30] Marintti, G.V., : ed. "Lipid Chromatography Analysis". Vol I Marcel Dekker. Inc., New York; 1967.

[31] Olofsson S-O, Boström P, Andersson L, Rurberg M, Perman J, Borén J. Lipid droplets as dynamic organelles connecting storage and efflux of lipids. Biochim Biophys Acta. 1791:448-8. 2009.

[32] Soulages JL, Wells MA. Lipophorin: the structure of an insect lipoprotein and its role in lipid transport in insects. Adv Protein Chem. 45:371-415; 1994.

[33] Skipski, V.P., Barclay, M., Reichman, E.S. and Good, J.J., : Biolchem, Biophys. Acta., 137, 801967.

[34] Van der Horst DJ, van Hoof D, van Marrewijk WJ, Rodenburg KW. Alternative lipid mobilization: the insect shuttle system. Mol Cell Biochem. 239:113-19; 2002.

[35] Venkatesh K, Morrison PE. Studies of weight changes and amount of food ingested by the stable fly, Stomoxys calcitrans (Diptera, Muscidae) Can Entomol. 112:141-49; 1980.

[36] Viogue, E, and Holaman, R.T., : Quantitative estimation of esters by thin layer chromatography., J.Am.oil. chemistis. Soc., 39, 68-66 1962.
[37] Wagner, H., Horhammer, L. and Wolfe, P.: Thin layer chromatography of phospholipids and glycolipids., Biochem., 2, 175-184; 1961 